\title{
Wilson Simonal em campo: reflexões sobre o álbum México 70
}

\author{
Renan Paiva Chaves (UNICAMP, Campinas, SP) \\ piratarix@gmail.com \\ Eduardo de Lima Visconti (UNICAMP, Campinas, SP) \\ eduvisconti@yahoo.com.br
}

\begin{abstract}
Resumo: Análise do álbum México 70 de Wilson Simonal, lançado pela gravadora Odeon mexicana em 1970. Buscamos compreender como as dimensões internas do disco, especialmente no que tange às orientações estético-musicais, condensaram alguns conflitos simbólicos presentes no processo de internacionalização da cultura e da consolidação da indústria fonográfica no Brasil. Após articular as relações entre futebol, imprensa, música popular e Estado com uma apreciação musical de cada faixa do álbum, confrontamos nossas conclusões com alguns conceitos recorrentes na literatura que trata da cultura e da música popular brasileira na década de 1970, a fim de sugerir um possivel enfoque analítico para pensar a relação entre música popular brasileira e o contexto político-cultural desse período.
\end{abstract}

Palavras-chave: Wilson Simonal; México 70; Música Popular Brasileira.

\section{Wilson Simonal in field: reflections on the album México 70}

\begin{abstract}
Analysis of Wilson Simonal's Mexico 70 album released in 1970 by the Mexican record label Odeon. We aim at understanding how the internal dimensions of the album, especially regarding the musical-aesthetic guidelines, condensed some symbolic conflicts present in the internationalization culture process and the phonographic industry consolidation in Brazil. After articulating the relations between soccer, media, popular music and the Brazilian State with a musical appreciation of each track on the album, we confronted our partial conclusions with some recurring concepts in the literature that deals with Brazilian culture and Brazilian popular music in the 1970s, in order to suggest a possible analytical approach to think the relation between Brazilian popular music and the political and cultural context of this period.
\end{abstract}

Keywords: Wilson Simonal; Mexico 70; Brazilian popular music.

\section{1 - Introdução}

Recentemente, a trajetória artística de Wilson Simonal tem sido objeto de alguns estudos. Dentre as pesquisas científicas de pós-graduação sobre o assunto podemos citar: "Quem não tem swing morre com a boa cheia de formiga: Wilson Simonal e os limites da memória tropical" (FERREIRA, 2007) e "A pérola negra regressa ao ventre da ostra: Wilson Simonal em suas relações com a indústria cultural (1963 a 1971) (HARTWIG, 2008)". Junto a estes trabalhos, o que se encontra são livros e textos jornalísticos que citam Simonal como um coadjuvante da história, além de relatos de pessoas que conviveram com ele, como ilustra o documentário Simonal - ninguém sabe o duro que dei, dirigido por Calvito LEAL, Cláudio MANOEL e Micael LANGER (2009). De um modo geral, se verifica que o foco analítico dessas pesquisas se pauta por uma descrição biográfica relacionada ao contexto político em que o músico desenvolveu sua carreira. Além disso, o que se nota nas representações historiográficas construídas sobre a MPB das décadas de 1960 e 1970 realizadas no calor do momento e também posteriores a ela, é a ausência de Wilson Simonal como participante dessas narrativas históricas.

Essa situação tem se modificado progressivamente nos últimos anos devido às produções supracitadas e à reedição de discos de Simonal que ocorreram nos anos posteriores a sua morte, em 2000. Um conjunto relevante de sua produção discográfica, referente ao período de 1961 a 1971, foi relançado em um Box com nove CDs pela gravadora Odeon/EMI no ano de 2004. 
Todavia, muitas lacunas e equívocos sobre sua carreira artística ainda estão em aberto. A partir dessa perspectiva, observamos a ausência de um estudo ou mesmo uma descrição mais aprofundada sobre o álbum México 70, lançado após a Copa do Mundo de 1970 no México'. Devido a este fato e tendo em vista as poucas pesquisas sobre Wilson Simonal, este artigo tenciona desenvolver um enfoque mais musicológico de sua produção artística, procurando perceber de que modo a forma e o conteúdo do repertório de seus álbuns - no caso, do disco México 70 - condensaram alguns conflitos simbólicos presentes na conjuntura sócio-política da época.

0 que vislumbramos nesse artigo está ligado à importância desse álbum, que remonta diretamente a um período no qual Wilson Simonal estava no topo de sua carreira em termos de vendagem de discos, com grande quantidade de shows, fama e dinheiro, e a um momento que ainda é pouco explorado em pesquisas sobre música popular. Como analisa Marcos Napolitano, a MPB foi o centro de mais um paradoxo presente na década de 1970, formado pela relação entre a afirmação de valores ideológicos através da canção e o consumo musical orientado por sofisticados mecanismos de mercado. Na argumentação do historiador, esse período sugere inúmeros problemas que ainda precisam ser decifrados pela investigação acadêmica (NAPOLITANO, 2002, p.11).

Pretendemos, portanto, analisar o repertório do álbum México 70 de Wilson Simonal relançado pela gravadora EMI no ano de 2010. Considerando-se a relação entre futebol, imprensa, música popular e Estado no Brasil, principalmente entre os anos das conquistas das Copas do Mundo de 1958, 1962 e 1970, articulada a uma análise das músicas que compõem o disco, procuramos refletir como esse disco condensou possíveis conflitos simbólicos presentes no universo sociocultural do final dos anos de 1960 e início da década de 1970 dentro de um processo de internacionalização da cultura e consolidação da indústria fonográfica no país.

\section{2 - Simonal e Pelé: música, futebol, imprensa e Estado}

No pós Segunda Grande Guerra, o futebol brasileiro já era um esporte fortemente regulado pelo governo, que articulava e garantia sua popularidade pelos jornais e rádios. Frente ao forte abalo que recebeu o futebol europeu devido às destruições físicas e organizacionais decorrentes da guerra, o futebol brasileiro ganhou força no plano nacional e reconhecimento internacional e começou a se tornar orgulho nacional (BRANCO, 2006). Em concordância com um contexto histórico de conturbação política e de mudança da percepção da questão social, no qual a identidade nacional é reformulada pela emergência de novos heróis e mitos (anos 1960) - ou seja, novos símbolos e ídolos nacionais, divulgadores e representantes legítimos de uma identidade reconstruída -, surge Pelé, consagrado, depois da conquista da Copa do Mundo de 1958 realizada na Suécia e dos títulos nacionais e internacionais pelo Santos Futebol Clube. Até 1960, mais de vinte canções o tiveram como tema e inúmeras biografias foram publicadas, além de ser alvo constante da grande imprensa: Pelé virou produto de consumo e símbolo nacional. Seu sucesso foi crescente até princípios dos anos 1970, quando se sagrou tricampeão pela seleção brasileira de futebol na Copa do Mundo do México.

Paralelamente, no campo musical, aparece Wilson Simonal, que iniciou sua carreira como cantor de bailes e como apresentador do programa "Os Brotos Comandam" em 1961. Em 1963, lançou seu primeiro disco autoral intitulado Wilson Simonal Tem Algo Mais, recheado de arranjos ao estilo bossanovista. Com uma sonoridade parecida com este trabalho, seguiu seu segundo álbum - A Nova Dimensão do Samba (1964). Em 1965, lançou seu terceiro disco, transitando entre diversos estilos de samba: interpretando Ary Barroso, Dorival Caymmi, Zé Ketti e Tom Jobim. Após outros trabalhos nessa mesma tendência, Simonal lançou, em 1967, uma canção, em estilo samba soul ${ }^{2}$, denominada Tributo a Martin Luther King (1967) ${ }^{3}$, trazendo à tona a temática da luta do negro frente às barreiras do preconceito: de certa forma Simonal representou essa luta no contexto brasileiro (HARTWIG, 2008).

Essa influência da soul music na obra de Simonal foi, possivelmente, orientada pelas carreiras de James Brown e Ray Charles nos Estados Unidos, pois esse gênero serviu de fundo musical para o engajamento desses artistas pela luta dos direitos civis dos negros na sociedade norteamericana (GONÇALVES, 2011) ${ }^{4}$.

A partir de então, Simonal entra na fase denominada pilantragem, que, segundo Carlos Imperial ${ }^{5}$, arranjador de muitas das gravações do cantor, era uma maneira mais "solta", dançante e swingada de se fazer arranjos e músicas. Algumas canções de sucesso nessa época foram: Meu Limão, Meu Limoeiro (1966), Nem Vem Que Não Tem (1967) e Sá Marina (1968).

Em 1968, Simonal já era uma das pessoas mais famosas do Brasil, disputando espaço com Roberto Carlos e Pelé, além de ter reconhecimento internacional (BOSCO, 2009). Nesse momento, podemos dizer que o artista se torna um dos símbolos nacionais: cantor sofisticado, afinado, cativante e eclético; assim como Pelé jogava, Simonal cantava. Com tremenda facilidade e autêntica habilidade, providos de "dom" e envoltos à noção de mito ${ }^{6}$, os dois representavam aquilo que de "melhor" havia no Brasil: o futebol e a música.

A partir da imposição do Al-5 em 1968, o ditador Médici, que assumiu a presidência do Brasil em 1969, frente à queda de popularidade do regime ditatorial, passou a utilizar o futebol para reconquistar algum prestígio com a população: começou a frequentar as tribunas do Flamengo, a participar da escalação e dos treinos da seleção brasileira, assim como a caracterizar e enfatizar o futebol como orgulho nacional, símbolo da identidade nacional brasileira, uma das belezas "naturais" do Brasil (BRANCO, 2006). 
Nesse periodo, anterior à Copa de 1970 do México, permeava na sociedade um clima ufanista. Wilson Simonal emplacou nesta fase um de seus maiores sucessos: País Tropical (1969), composta por Jorge Ben em homenagem ao Flamengo, após a conquista do campeonato nacional brasileiro (mesclando, na letra, o futebol a outros elementos de uma "brasilidade" que emergia, como o fusca e o carnaval). Simonal, com sua carreira ascendente, virou garoto-propaganda da poderosa Shell, que com perspicácia, o associou ao carro e ao futebol, lançando-o em revistas, jornais, televisão e rádio. Não demorou muito para o poder público e a imprensa associarem a imagem de Pelé e a de Simonal. Segundo Adriane Hartwig:

\begin{abstract}
A Shell estava buscando em Simonal uma imagem para vincular à sua empresa, que agora, de capital nacional, quer reforçar sua presença no território nacional. Simonal, como um cantor popular, que transitava por diversos públicos, seria o que eles denominaram de "representante da classe trabalhadora", legitimando suas ações no país, vinculando a imagem da empresa a um símbolo de brasilidade. A escolha por Simonal se dá muito em função de sua popularidade e de seu fácil trânsito pelos mais variados grupos, o que interessa à empresa que necessita de uma imagem, de um símbolo que a identifique positivamente no país. De 1969 até 1971, Simonal será o símbolo de uma empresa estrangeira, recém nacionalizada, buscando sua permanência no mercado nacional de combustiveis. Para tanto, a mesma patrocinou shows e apresentações de Simonal, que a partir de então, divulgou o nome da empresa em eventos por ela criados. Uma das primeiras tarefas de Simonal seria a de ajudar a buscar fundos para financiar a seleção brasileira de futebol, que participou da Copa do Mundo de Futebol, no México (HARTWIG, 2008, p.112).
\end{abstract}

Não se pode perder de vista que o futebol não é apenas um esporte, consiste também em um jogo a serviço de um complexo de valores e relações sociais, no qual a população exercita o que é ser brasileiro. Nesse sentido, a construção sociocultural brasileira é permeada e coadjuvada pelo futebol: pensar suas relações com as outras manifestações consiste numa reflexão de essencial importância (DAMATTA, 1982).

\section{3- Dimensões internas e externas da produção do álbum México 70}

Em 1970, após uma turnê pela Europa, Simonal acompanhou a delegação da seleção brasileira na Copa do México, sendo lá quase um representante oficial. Com a vitória da seleção brasileira e com o sucesso das apresentações do cantor, a Odeon mexicana lançou o disco México 70 (1970), encabeçado pela música que então se tornaria sucesso: 0 samba "eletrificado" Aqui é o País do Futebol, composto por Fernando Brant e Milton Nascimento para o documentário Tostão - A fera de Ouro de 1970, que, na voz de Simonal, exalta o país e o futebol como paixões nacionais e os associam ao samba (emblemática frase da canção: "Olha o sambão, aqui é o país do futebol").

A segunda faixa é um arranjo em ritmo de shuffle de Raindrops Keep Falling On My Head, canção feita para o filme Butch Cassidy and the Sundance Kid (1969), e que, em 1970, ficou durante quatro semanas no primeiro lugar da lista "Hot 100", da revista Billboard". A terceira é Kiki, composta por Simonal e que possui influência da pilantragem. A quarta e a quinta faixas, Ave Maria no Morro e I'll Never Fall In Love Again (produzida para o musical Promises, Promises de 1968 e que ganhou 0 Grammy de melhor música de 1969) são versões no estilo samba soul. A sexta faixa, Crioula, é estruturada sobre ritmos afro-brasileiros, que se misturam com outras referências nacionais. A sétima, Que Pena, consiste em mais uma versão de um samba "eletrificado". A faixa oito é o medley The Age of Aquarius, feita para o musical rock Hair (1968): a primeira parte, Aquarius, é um arranjo "abrasileirado" com uma tradução da letra original para o espanhol; a segunda, The Flesh Failures, é cantada em português e mescla marcha, elementos da música pop, gospel e da salsa. A música nove é uma versão sambajazz de Garota de Ipanema.

A faixa dez é a canção italiana Ecco /l Tipo (Che lo Cercavo), num arranjo que se aproxima da pilantragem. As Menininhas do Leblon (uma sátira à Garota de Ipanema) é a faixa onze, num arranjo funk/soul próximo ao estilo consolidado por James Brown. A última música do disco consiste em uma versão em jazz-waltz de uma composição de Lamartine Babo e Francisco Mattoso denominada Eu Sonhei que Tu Estavas tão Linda.

As canções Que Pena e The Age of Aquarius, segundo Max de Castro $^{8}$, foram gravadas no segundo semestre de 1969, em meio às gravações do quarto volume do álbum Alegria! Alegria! (1969). Não se sabe ao certo qual era o destino concebido para essas faixas, se foram excluídas do disco ou se havia a intenção de incluí-las em lançamento de compactos. A canção intitulada Ecco II Tipo (Che lo Cercavo) foi lançada no primeiro semestre de 1970, na Itália, durante uma turnê de Simonal pela Europa, num compacto que foi dividido com uma versão em italiano de País Tropical. As outras faixas teriam sido gravadas nos estúdios da Odeon no Rio de Janeiro, conforme indicam os registros, no primeiro semestre de 1970, após a chegada de Simonal da Europa. De acordo com depoimento de Wilson Simoninha ${ }^{9}$ e os comentários da contracapa original do LP, os arranjos que entraram para o álbum México 70 compunham, provavelmente, os shows de enorme sucesso que o cantor emplacou ao longo de três meses, os quais antecederam e se firmaram durante a Copa do México.

No Brasil, durante o entusiasmo da imprensa com a Copa, um compacto duplo contendo quatro das músicas do álbum México 70 (Kiki, As menininhas de Leblon, Aqui é o País do Futebol e Eu Sonhei que Tu Estavas tão Linda) foi produzido, segundo Max de Castro, com a intenção de:

"[segurar], talvez, o lançamento de um álbum para a volta do artista ao Brasil. Com o êxito da seleção e de Simonal, a Odeon mexicana se adiantou e editou por lá um álbum inédito chamado México 70, logo após a Copa"10.

Simonal, nesses anos que compreendem 1968 a 1970, manteve uma média de trinta apresentações mensais. 
Seu sucesso comercial no Brasil ultrapassava os limites do mercado musical, associando-se também ao consumo de outros bens materiais e simbólicos. E em contato com Herb Alpert, sócio da ActM Records, empresa responsável pela projeção internacional de Sérgio Mendes, a carreira internacional de Simonal se mostrava num caminho promissor (ALEXANDRE, 2009).

Podemos afirmar que o repertório e os arranjos desse álbum refletem com bastante sintonia os argumentos de Eduardo VICENTE (2008) sobre produção, consumo e segmentação do mercado fonográfico no Brasil. 0 repertório internacional que, entre 1965 e 1967 centravase nas produções em espanhol, italiano e francês, e que, a partir 1970, tendeu ao inglês, está presente numa representativa configuração em México 70: uma música em espanhol, uma em italiano e três em inglês. Dentro dessa segmentação, nota-se ainda a crescente importância de músicas de trilhas sonoras de filmes e musicais no mercado, que no álbum de Simonal são quatro. A bossa nova, segmento especialmente forte até 1965, começa a dividir espaço no mercado fonográfico com arranjos que remetem a outros estilos de samba, apesar da presença marcante no disco de um arranjo sambajazz de Garota de Ipanema.

Os gêneros norte-americanos de sucesso como o soul e o funk, que se tornariam um importante segmento a partir de 1971, já estão incorporados em várias faixas (o que na expressão de Simonal seria o "samba soul"). Concomitantemente às tendências que emergiam através da segmentação do mercado fonográfico, podemos notar um ecletismo presente nos arranjos de cada faixa do disco. Diante disso, pretendemos investigar detalhadamente, mais adiante, como fatores externos da produção do disco se articulam ao conteúdo estético-musical do álbum.

\section{4 - Conflitos simbólicos presentes na música popular brasileira dos anos de 1970}

Quatro línguas cantadas num mesmo disco, misturas de gêneros, arranjos de temas internacionais e a incorporação de elementos estrangeiros podem estar relacionados àquilo que Renato ORTIZ (2001) apontou, mesmo não se referindo especificamente à música (mas à cultura, de maneira ampla), como substituição do caráter nacional-popular pelo internacional-popular no campo cultural na década de 1970. Mas não deixamos de notar, como Rita MORELLI (2008) o fez, que a aplicabilidade dos conceitos de Ortiz à música popular brasileira referente a essa substituição não se concretiza na década de 1970, já que se percebe ainda, majoritariamente, pelo menos até a década de 1990, uma expressiva produção musical orientada e estruturada por referências nacionais.

Sobre o contexto que marca a passagem dos anos de 1960 para os anos de 1970, Luiz Tatit afirma, além da polarização entre nacional e internacional, que:
Configurou-se a ideia de que a canção brasileira se alimenta de todas as dicções musicais circulantes no pais, sejam elas provenientes de outras culturas, de outros tempos, do mercado de consumo, das correntes de vanguarda, do mundo "brega", dos mais diferentes gêneros rítmicos, e de que, em princípio, nada deveria ser excluido (TATIT, 2005, p.121).

Dentro dessa noção ainda "vingou na música popular dos anos 70 a música sem fronteiras rítmicas, históricas, geográficas e ideológicas"11 (TATIT, 2005, p.121).

Restringindo-se ao que considera MPB e trabalhando sob conceitos dicotômicos, Marcos NAPOLITANO (2005, p.126) afirma que dentro das várias conotações que abarcam o que é MPB, há uma noção de que seu conceito é "inseparável de uma cultura política marcada pelo chamado 'nacional-popular' de esquerda", que esteve dentro de um campo de tensão ao longo da década de 1960, e que tentou equilibrar uma MPB moderna dentro daquilo que fosse ao mesmo tempo nacional e cosmopolita, lidando com dilemas da modernização capitalista dos anos de 1960 e 1970, tais como: tradição e ruptura, engajamento e vanguarda, populismo e revolução, folclore e erudição, cultura popular e indústria cultural. 0 historiador afirma também que, especificamente no que tange à MPB dos anos de 1960 e 1970, esses dilemas se faziam "presentes no próprio material estético das canções e não apenas no contexto sociológico que elas, como se diz corriqueiramente, 'refletiriam'". E conclui: "Na minha opinião, mais do que 'espelho' que reflete algo, a música (e a cultura como um todo) é o caleidoscópio pelo qual o objeto visado (a 'realidade social') se dinamiza e se reconfigura" (NAPOLITANO, 2005, p.127).

Com interesse nesse chamado "material estético das canções" a que se refere Napolitano quando discorre sobre MPB, que não apenas reflete, mas que revela e interage com aspectos das configurações sociais e culturais, analisamos alguns elementos dos arranjos das canções que compõem o álbum México 70 que, como afirmado, estão em grande sintonia com a segmentação da indústria fonográfica nos entornos de 1970, a fim de compreendermos como esses conflitos simbólicos sinalizados pelos autores acima citados podem se mostrar num âmbito mais estrutural das músicas.

\section{5 - Apontamentos analíticos do repertório}

Abaixo sistematizamos uma análise musical sintética tendo em vista a problemática exposta acima, para mais adiante retomarmos a discussão. As faixas seguem a ordem do disco.

1) Aqui é o País do Futebol - composta por Milton Nascimento e Fernando Brant como parte da trilha sonora de um documentário lançado em 1970, antes da Copa, sobre o jogador da seleção brasileira Tostão. No arranjo do álbum, a música é um samba de "segunda geração", de acordo com critérios de classificação de Eduardo VICENTE (2008). Esse estilo de samba se pauta 
por uma vocação mais pop e urbana, à qual os nomes de Wilson Simonal e Jorge Ben se atrelam fortemente. Tais produções se mantiveram associadas à nomenclatura "samba-rock", que, dentro da segmentação da indústria fonográfica, ganhou importância a partir de meados da década de 1960, principalmente a partir de 1967. Segundo Vicente, Wilson Simonal e a Turma da Pilantragem foram importantes artistas desse segmento, no que diz respeito ao consumo fonográfico entre 1965 e 1970.

Apesar de ser encarada como um "sambão", como certos trechos da letra da própria canção enfatizam ("Olha o sambão, aqui é o país do futebol"), pode-se notar no arranjo a presença de elementos de gêneros internacionais, como a levada funky da guitarra elétrica e a condução das convenções ritmo-melódicas dos sopros num modelo próximo aos arranjos de canções soule funk da década de 1960 e 1970. Ou seja, em linhas gerais o samba, tomado como autêntica manifestação da cultura brasileira estava, nesse caso, permeado de elementos recorrentes da música internacional. Contudo, o imperativo samba é 0 que se mostra mais vigorante e estruturante, e pode ser identificado no desenho rítmico do contrabaixo, realizado em padrões regulares de colcheia pontuada e semicolcheia e apoiado pela condução rítmica da bateria, como também, nas intervenções do coro vocal e naipe de sopros.

2) Raindrops Keep Falling On My Head - canção produzida para a trilha sonora do filme Butch Cassidy and the Sundance Kid (1969). Estourou nas paradas de sucesso de vários países entre 1969 e 1970, como nos indicam alguns rankings deste periodo, entre eles: Canadian RPM adult contemporany, French Singles Chart, Italian Singles Chart, UK singles chart, U.S. Billboard hot 100 e U.S. Billboard adult contemporany. Para VICENTE (2008), o repertório internacional teve, nos anos 1970, um dos melhores períodos de vendagem no mercado brasileiro. Dentro desse segmento estão incluídos, além das coletâneas de artistas nacionais e internacionais que cantavam inglês, as trilhas sonoras de filmes e de musicais importados.

0 arranjo presente na gravação é o que se convenciona chamar de estilo shuffle, que remete diretamente ao jazze ao blues cantado e a uma condução rítmica que enfatiza os segundo e o quarto tempo, considerando-se um compasso quaternário. Em contraste com a primeira faixa do disco, na qual o samba, apesar de se mostrar vigoroso, aparece permeado de detalhamentos estilísticos advindos de outros gêneros, Raindrops Keep Falling On My Head, mesmo mantendo firme sua estética shuffle, sofre uma inserção abrupta de um interlúdio instrumental em samba-rock ${ }^{12}$. Há aí uma certa inversão entre os guias estruturais da primeira e da segunda música do álbum. Se na primeira o samba (nacional) cedia espaço ao internacional, na segunda, o internacional cede espaço ao samba.

3) Kiki - canção composta por Nunato Buzar e Wilson Simonal. 0 arranjo dessa música se assemelha a muitos outros da época da pilantragem, que possuíam uma sonoridade pop influenciada por gêneros internacionais. Como afirma Carlos Imperial, os arranjos da pilantragem são mais "soltos", dançantes e swingados. Na análise de Gonçalves, uma das características principais desse estilo "estava na maneira de tocar o samba - em compasso quaternário em vez de binário - inspirado no rock e no soul norte-americanos" (GONÇALVES, 2011, p.37). 0 soul'13 teve enorme projeção internacional na década de 1960 e penetrou com maior intensidade no mercado musical brasileiro na década de 1970 (incluindo-se aqui também o funk), mais especificamente a partir de 1971, influenciando carreiras brasileiras de sucesso como a do cantor Tim Maia.

Interessante notar como Vicente observa a assimilação desses gêneros importados no Brasil:

Tentei reunir nessa categoria [soul/ funk/ rap] aqueles cujas obras se ligam à música negra norteamericana. Trata-se de um grupo de artistas que, tal qual os do rock, encontram no que é mundializado seu primeiro referencial e, se chegam a dialogar com a tradição musical nacional, fazem-no a partir dessa base, e não o contrário. (VICENTE, 2008, p.119)

Tanto Gonçalves como Vicente, apesar de tomarem como ponto de partida referenciais distintos em relação à incorporação desses gêneros estrangeiros no Brasil, mostram como se fazia presente a articulação entre 0 nacional e o internacional nas estruturas internas de expressiva produção musical da época, independentemente de qual desses elementos se mostrava mais imperativo.

Percebe-se também na gravação dessa faixa um ritmo "abolerado" e a presença de sopros com intervenções em frases melódicas comuns ao jazz. Há instrumentos de percussão da música popular afro-cubana num primeiro plano que, acrescidos de levadas ao piano, acentuam um balanço latino-americano. No arranjo dessa música transparece um caldeirão de elementos nacionais e internacionais que resulta numa mistura de ritmos e sonoridades de difícil classificação.

4) Ave Maria no Morro - uma regravação no estilo samba soul da composição de Herivelto Martins de 1942. Apesar dos arranjos da pilantragem, como mencionamos anteriormente, já lidarem com o soul, em Ave Maria no Morro notamos uma maior presença e maior similaridade da música com esse gênero norteamericano que começaria a ganhar importância no Brasil na década de 1970: os elementos que se ligam ao soule funk no arranjo estão mais evidentes, principalmente na levada de bateria e baixo.

Outros recursos podem ser observados como a utilização dos sopros em staccato, a forma de acompanhamento dos coros e os riffs de piano, que remetem ao gospel norteamericano e revitalizam o significado religioso da letra - "E o morro inteiro/ no fim do dia/ reza uma prece/ Ave Maria"; "E quando o morro escurece/ elevo a Deus uma prece". 
5) I'Il Never Fall In Love Again - canção que faz parte da trilha sonora produzida para o musical Promises, Promises (1968), e que ganhou o Grammy de melhor música de 1969. Na versão de Simonal se torna um samba soul. Distintamente da faixa anterior, na qual o viés soul se encontra no horizonte do gospel, em I'll Never Fall In Love Again se nota um toque mais voltado para o funk e o blues, especialmente na interação entre os sopros com a levada da bateria e do contrabaixo nos interlúdios instrumentais. Entretanto, é interessante observar as diferentes conduções e mudanças de instrumentação nas partes cantadas, que não seguem uma levada funk necessariamente, mas de certa forma se localizam dentro de gêneros internacionais originários da black music. A base harmônica também segue cadências de acordes dominantes comum ao blues, e o canto por vezes enfatiza, através de uma inflexão bluesy, a palavra "again", acentuando o significado principal da letra, baseado na desilusão amorosa.

É importante apontar como existe uma distinção clara no arranjo entre as seções que antecedem e sucedem a parte cantada, no que diz respeito à mudança de estilos baseados em ritmos do blues, do rock e do funk.

6) Crioula - canção de autoria de Jorge Ben. Na versão do álbum, logo na introdução, são misturados ritmos de origem afro-brasileira, como o toque de candomblé, com riffs, aparentemente improvisados, de piano e flauta, e que remetem à soul music. Outro procedimento de procedência africana é a polirritmia criada entre o ritmo da melodia, que sustenta uma das frases principais da música ("Uma linda dama negra") com a base.

A condução rítmica que apóia a melodia principal persiste com elementos afro-brasileiros e se misturam, em determinado trecho da gravação, com uma levada de baião executada pelo contrabaixo. 0 desfecho da música incorpora uma expressão blues tanto nas inflexões da voz, como no toque do piano.

7) Que Pena - música de autoria de Jorge Ben, datada de 1969. Na versão de Simonal compartilha muitas semelhanças com o arranjo de Aqui é o País do Futebol. Todavia sua estrutura é mais voltada para o samba, ou seja, os acentos no segundo tempo (considerando um compasso de dois tempos) são mais nítidos na elaboração do arranjo, principalmente se observarmos a levada da bateria e do contrabaixo. A sustentação harmônica é reforçada pelo naipe de sopros sincopados que acrescentam balanço ao ritmo do samba e participam das diversas convenções rítmicas.

8) 0 medley Aquarius / The Flesh Failures, tal como I'll Never Fall In Love Again, foi composto para um musical (no caso o musical rock Hair de 1968). A primeira parte da música foi "abrasileirada" ${ }^{14}$ e a concepção do arranjo é muito parecida com a da faixa anterior, mas com a distinção de uma levada, nas introduções, em ritmo de samba-rock. Na primeira parte, a letra, original em inglês, é cantada em espanhol. De certa forma, aí, se juntam dois elementos de universos distintos: o samba, brasileiro, e a língua espanhola, que remete ao universo latino-americano. A segunda parte The Flesh Failures é, por outro lado, cantada em português. Entretanto, o que se nota agora é presença de uma grande mescla de diferentes elementos musicais, que circundam entre 0 ritmo da marcha, vocalização gospel, piano "salseado" e bateria com levada de rock.

9) Garota de Ipanema - canção emblemática da bossa nova de autoria de Tom Jobim e Vinícius de Moraes, gravada em 1962. Nesta releitura, o arranjo se aproxima de uma estética mais estridente oriunda do sambajazz, revelada na introdução formada por naipes de metais e madeiras em bloco tocados com grande intensidade. Apesar de a bossa nova se constituir como símbolos de "bom gosto" e refinamento musical, Vicente aponta que sua presença diminuiu no mercado de consumo a partir de meados da década de 1960, cedendo lugar ao samba e a gêneros internacionalizados. Diante desse panorama, nota-se como as configurações e escolhas dos arranjos do álbum estavam sintonizadas com tendências musicais decorrentes da segmentação do mercado e consumo fonográfico.

Observa-se no arranjo, a forte presença do samba e do jazz. Ao longo da música, a separação auditiva desses dois gêneros se faz perceptível, apesar de, em certos trechos, o samba incorporar traços estilísticos do jazz como a improvisação de novas melodias instrumentais sobre o pano de fundo harmônico realizado pelo naipe de sopros. Em outras palavras, é como se os dois domínios se relacionassem na música paralelamente, o que permite o reconhecimento de musicalidades presentes em cada estética.

10) Ecco II Tipo (Che lo Cercavo) - música italiana composta por Tristano, Simoni e Pontiack em 1970. Esse fonograma é outro exemplo no qual ocorre intercâmbios de estilos e estéticas. Possui uma sonoridade próxima à da pilantragem, recheada com intervenções do naipe de sopros e uma base rítmica abrasileirada na primeira parte, que se reconfigura numa levada pop com influência do shuffle em alguns trechos.

11) As menininhas do Leblon - música de autoria de Silvio Cesar, feita em 1970, uma possivel sátira com Garota de Ipanema, que ilustra, através da letra, como gêneros internacionais estão mais em voga que a bossa nova ("Ipanema não dá mais pé/ o Leblon agora é que é/ que me desculpe o amigo Tom/ Garota de Ipanema já era hein/ agora é Menininhas do Leblon"; "sua discoteca é demais/ lá não entra disco pra trás/muito swing muito som/ olha aí bonequinha/ no gogó/ Menininhas do Leblon").

A sonoridade da base e do arranjo se baseia no funk e no soul norte-americano, possuindo grande similaridade com algumas gravações de James Brown. Entre esses recursos, temos a modulação brusca da parte cantada 
para interlúdios instrumentais estruturados por naipes de sopros estridentes e a levada da seção rítmica bem característica do gênero do funk.

12) Eu Sonhei que Tu Estavas tão Linda - canção composta por Lamartine Babo e Francisco Mattoso em 1941. Na versão de Simonal a canção é adaptada para um arranjo em jazz-waltz, com destaque para o acompanhamento de naipes de sopros e um contraponto de violino.

\section{6 - Algumas considerações}

Após uma análise abrangente sobre as estruturas musicais dos arranjos de cada faixa do disco, confrontamos nossas conclusões parciais com os estudos de Ortiz, Morelli, Napolitano e Tatit sobre a década de 1970.

Como detalhado, a grande mistura de estilos e sonoridades de gêneros nacionais e internacionais presentes no álbum México 70 aponta para a presença de elementos que podem ser associados a uma cultura nacional-popular imbricados com outros internacionalizados, o que permite inferir a impossibilidade de uma substituição abrupta dessas referências nas estruturas constitutivas de nosso objeto de estudo. Por outro lado, é notável a compatibilidade de concepções musicais do álbum com tendências que se constituíam dentro da segmentação do mercado fonográfico. Entre elas, alguns elementos vinculados a uma noção de exterioridade ou internacionalidade, ou seja, identificados como pertencentes à cultura de outros países ou a uma música de padrão internacional (estandardizada). 0 que está completamente vinculado ao momento de consolidação do mercado de consumo no Brasil e ao processo de internacionalização do capital, que foi guiado por diretrizes político-econômicas do governo brasileiro num dos períodos mais severos da ditadura -, e que abriram e aumentaram as relações com outros países, pelo menos no que diz respeito à circulação de mercadorias.

Entretanto, vale clarificar alguns pontos que nos parecem essenciais, no que diz respeito ao âmbito da estrutura musical, à diferença de uma música de padrão internacional daquela permeada por elementos internacionais. Nesse sentido, recorremos à noção de fricção de musicalidades desenvolvida por Acácio PIEDADE (2011). Para o pesquisador, musicalidade é aquilo que se conforma como um conjunto de elementos musicais e simbólicos compartilhados por uma comunidade de pessoas. Sobre as origens do conceito de fricção, Piedade se baseia em estudos de antropologia que utilizam o termo:

Cardoso de Oliveira desenvolveu este conceito a partir dos anos 60 , para dar conta da relação entre sociedades indigena e a sociedade brasileira, que ele via como conflituosa. 0 conflito, inerente à situação de fricção interétnica, se explica pelos interesses diversos das sociedades em contato, sua vinculação irreversivel e interdependência, e pela situação de domínio e submissão ali engendrada. Neste conceito, Cardoso de Oliveira se afasta da ideia de transmissão, aculturação ou assimilação, ligadas ao paradigma culturalista anterior, desenvolvido principalmente por Darcy Ribeiro (1970). 0 enfoque passa, da mudança cultural, para a interação continuada entre duas sociedades, que formam um sistema intersocietário que exibe, em seu cerne, uma desigualdade (PIEDADE, 2011, p.199).

Piedade cria, então, a expressão fricção de musicalidades a partir da observação de que há situações nas quais as musicalidades dialogam, mas não se misturam, permanecendo fronteiras musical-simbólicas que insistem em afirmar as diferenças em vez de uma síntese entre as musicalidades.

0 discurso dos músicos, críticos e apreciadores fala de fusão, sincretismo, mistura, influência. Estas noções somente fazem sentido através da distinção que Ihes é implícita: o "novo" gênero "absorve" uma musicalidade outra que, no entanto, mantêm-se distinta justamente porque é percebida (PIEDADE, 2011, p.201).

Apesar de tais noções haverem sido empregadas por Piedade em relação a uma música instrumental brasileira, parece-nos, mesmo tratando-se dos arranjos da canção, que elas se mostram mais interessantes para esclarecer e ampliar o horizonte das configurações musicais que as concepções dicotômicas, como nacional-popular e internacional-popular ou nacional e cosmopolita. Esses modelos são comumente utilizados para entender, de maneira ampla, a música popular brasileira dos anos 1960 e 1970, mas que de certa forma acabam ficando aquém da estrutura musical propriamente dita.

Com as análises musicais que fizemos, tais dicotomias, apesar de serem importantes parâmetros num horizonte amplo, não parecem dar conta das especificidades das elaborações dos arranjos musicais, nos quais não se nega a presença do internacional, mas que tampouco se configuram como um padrão internacional. Revelam assim, um campo de disputas no qual o nacional e o internacional, entre outros embates, se relacionam para além dos conceitos de fusão e mistura, e o material estético de cada canção, em vez de "refletir" mecanicamente o contexto sócio-político, traduz ambiguamente esses dilemas através do diálogo conflituoso entre as diversas musicalidades.

Para além do nosso objeto de estudo, cabe-nos lançar, como hipótese, que tais ideias, principalmente a que aponta uma diferença marcante entre música de padrão internacional e música permeada por elementos internacionais, podem oferecer uma contribuição para se pensar a música popular brasileira no período de fins da década de 1960 e princípios da década de 1970, que se constituiu dentro do processo de internacionalização da cultura. Contudo, nossa investigação ainda carece de aprofundamento e extensão para tentar compreender até que ponto os arranjos e a sonoridade dos discos da década de 1970 condensaram em suas dimensões internas questões pertinentes ao andamento histórico no qual estavam inseridos. 


\section{7 - Referências}

ALEXANDRE, R. Não vem que não tem: A vida e o veneno de Wilson Simonal. Rio de Janeiro: Ed. Globo, 2009.

BOSCO, F. Mó num pá tropi: a graça e a desgraça de Wilson Simonal. In: Revista Cult, n. 138, São Paulo: Ed. Bregantine, 2009.

CHAVES, R. P. País Tropical e seu mimetismo: o discurso ufanista associado a Wilson Simonal e a desinvenção tropicalista. In: Revista de Ciências Humanas, v. 44, n. 2, Florianópolis: UFSC, 2010.

BRANCO, C. Os papéis sociais do futebol brasileiro revelados pela Música Popular (1915-1990). In: TEIXEIRA DA SILVA, F.; SANTOS, R. (Org.) Memória social dos esportes: futebol e política: a construção de uma identidade nacional. Rio de Janeiro: Mauad X: FAPERJ, 2006.

DAMATTA, R. Esporte na sociedade: um ensaio sobre o futebol brasileiro. Universo do futebol: esporte e sociedade brasileira.. Rio de Janeiro: Editora Pinakotheke, 1982.

FERREIRA, G.A.A. Quem não tem swing morre com a boca cheia de formiga:Wilson Simonal e os limites de uma memória tropical. Niterói: UFF, 2007. Dissertação de Mestrado.

GONÇALVES, Eloá G.. Banda Black Rio: O Soul no Brasil na década de 70. Campinas: UNICAMP/IA, 2011. Dissertação de Mestrado.

HARTWIG, A. A pérola negra regressa ao ventre da ostra: Wilson. Simonal em suas relações com indústria cultural (1963 a. 1971). Marechal Cândido Rondon: UNIOESTE, 2008. Dissertação de Mestrado.

MORELLI, R. O campo da MPB e o mercado moderno de música no Brasil:do nacional-popularà segmentação contemporânea. In: Revista ArtCultura, Uberlândia, v. 10, n. 16, jan.-jun. 2008

NAPOLITANO, M. MPB: totem-tabu da vida musical brasileira. In: Anos 70: trajetórias. São Paulo: Itaú Cultural/Iluminuras, 2005.

. A música popular brasileira (MPB) dos anos 70: resistência política e consumo cultural. In: Anais do IV Congresso da IASPM-AL, México, 2002.

ORTIZ, R. A moderna tradição brasileira. São Paulo: Brasiliense, 2001.

PIEDADE, A. Perseguindo os fios da meada: pensamentos sobre hibridismo, musicalidade e tópicas. In: Per Musi. Belo Horizonte: UFMG, n.23, 2011.

TATIT, L. A canção moderna. In: Anos 70: trajetórias. São Paulo: Itaú Cultural/Iluminuras, 2005.

VICENTE, E. Segmentação e consumo: a produção fonográfica brasileira - 1965/1999. In: Revista ArtCultura, Uberlândia: UFU, v. 10, n. 16, p.103-121, jan.-jun. 2008

\section{Discografia}

Wilson Simonal - México 70. Odeon, 1970.

\section{Filmografia}

SIMONAL - ninguém sabe o duro que dei. Direção de Calvito LEAL, Cláudio MANOEL e Micael LANGER. Rio de Janeiro: Biscoito Fino Brasil, 2009. DVD

\section{Notas}

1 Tal falta pode se justificar pelo fato do álbum ter sido somente relançado no ano de 2010. Á época do lançamento do Box da Odeon, os produtores do projeto, Max de Castro e Wilson Simoninha podem não ter se dado conta da existência do disco México 70

2 Discutiremos posteriormente essa vertente do samba.

3 Essa música, além de integrar o repertório dos shows de Simonal no ano de 1967, fez parte, no mesmo ano, de um compacto simples, um duplo e do álbum Show em Simonal, todos produzidos pela Odeon.

4 Essa consideração de Eloá Gonçalves é baseada em: SHUKER, Roy. Vocabulário de música pop. São Paulo: Ed. Hedra, 1999. p.35.

5 Conferir o texto "Nascimento, Mudanças e Apogeu da Pilantragem de Carlos Imperial", contido no encarte do LP Pilantrália - Carlos Imperial e a Turma da Pilantragem, de 1968.

6 A relação entre Simonal, Pelé, dom e mito foi trabalhada noartigo: CHAVES, R. P. País Tropical e seu mimetismo: o discurso ufanista associado a Wilson Simonal e a desinvenção tropicalista. In: Revista de Ciências Humanas, v. 44, n. 2, Florianópolis: UFSC, 2010.

7 Conferir em: <http://www.billboard.com/bbcom/specials/hot100/charts/top100-titles-90.shtml>. Acesso em fev. 2012

8 Conferir em: <http://emi.com.br/site/index.php?option=com_content\&tview=articlectid=192: wilson-simonal-mexico-70\&tcatid=11:produtos\&tlem id=48>. Acesso em fev. 2012.

9 Idem.

10 Idem.

11 Embora as fronteiras entre gêneros, estilos e ideologias não sejam rígidas no disco México 70, vale frisar que essa afirmação de Tatit parece desconsiderar uma parcela da produção musical dos anos 1970 que se voltou para regionalismos (como o samba "das comunidades" de Martinho da Vila e Candeia), e outra que persistiu com uma posição ideológica crítica (como Chico Buarque).

12 Interessante notar que na versão original, veiculada no formato audiovisual no filme Butch Cassidy and the Sundance Kid (1969), há também uma quebra abrupta da canção, com fins narrativos na sequência de "amor" de Butch (Paul Newman) e Etta Place (Katharine Ross). Fora do contexto 
narrativo do filme, é evidente que essa quebra foi tomada como parte constituinte da canção, sendo transformada num interlúdio.

13 Cabe aqui delimitar alguns sentidos do termo soul: acreditamos que o uso do termo soul remonta a uma música que compartilha estruturas provindas do gospel, do blues e do jazz, e que começou a se consolidar como gênero musical a partir da década de 1950 e 1960. Também influenciou os gêneros do funke da disco music dos anos de 1970 e 1980 . Sua origem é norte-americana e teve uma vinculação com movimentos de afirmação de minorias, em especial, da emancipação do negro e sua luta por direitos civis.

14 Originalmente o arranjo se caracteriza como rock.

Renan Paiva Chaves é Graduando em Música Popular pela Universidade Estadual de Campinas. Em 2010, participou como bolsista do convênio entre a UNICAMP e a Universidad Nacional del Litoral, onde desenvolveu pesquisas sobre a música popular e folclórica argentina. Foi bolsista de iniciação científica pela FAPESP na área de trilhas sonoras para cinema e possui artigo publicado na Revista de Ciências Humanas da UFSC e na Revista Estudos e Pesquisas em Psicologia da UERJ.

Eduardo de Lima Visconti é Bacharel em Música Popular pela Universidade Estadual de Campinas (UNICAMP), Mestre e Doutor em Música (UNICAMP). Desenvolve pesquisas nos seguintes temas: etnomusicologia, música popular, musicologia, ideologia, identidade cultural, análise musical, arranjo, improvisação, harmonia, guitarra e violão. Foi professor temporário durante 5 anos (2007-2012) de Guitarra elétrica (I-VIII) e Prática de Conjunto (I-VIII) na graduação em música popular da UNICAMP. Participou, em julho de 2012, como professor de guitarra/violão e improvisação na música popular no IX Festival de Música em Ibiapaba no Ceará. Atualmente, iniciou pesquisa de pós-doutorado no Instituto de Estudos Brasileiros (IEB -USP) sobre arranjo e sonoridade no samba da década de 1970, com supervisão do prof. Dr. Walter Garcia e bolsa de pós-doutorado júnior do CNPq.Tem se apresentado regularmente com seu trio e quarteto no Brasil e no exterior. 